OPEN ACCESS

Edited by:

Haiyan Zhu,

Chengdu University of Technology,

China

Reviewed by:

Yongcun Feng,

China University of Petroleum, Beijing,

China

Fanhui Zeng,

Southwest Petroleum University,

China

${ }^{*}$ Correspondence:

Hao Liang

lianghao8@cnooc.com.cn

Specialty section:

This article was submitted to

Economic Geology,

a section of the journal

Frontiers in Earth Science

Received: 26 September 2021

Accepted: 07 February 2022

Published: 02 March 2022

Citation:

Xu C, Liang H and Guo S (2022)

Characteristics of Porosity and

Permeability of Ultra-High

Temperature Perforated Damage Zone

in Sandstone Targets.

Front. Earth Sci. 10:783556.

doi: 10.3389/feart.2022.783556

\section{Characteristics of Porosity and Permeability of Ultra-High Temperature Perforated Damage Zone in Sandstone Targets}

\author{
Changgui $X u^{1}$, Hao Liang ${ }^{2 *}$ and Shusheng Guo ${ }^{2}$ \\ ${ }^{1}$ Exploration Department of CNOOC Ltd., Beijing, China, ${ }^{2}$ CNOOC (China) Co., Ltd., Haikou, China
}

Perforating as a widely-applied stimulation technology is becoming incrementally important in unconventional oil/gas development. It can effectively improve deep-lying high-temperature, high-pressure (HTHP), low-porosity, low-permeability reservoirs, eliminate near-wellbore surface pollution, and increase drainage area. Characteristics of damage zone porosity directly reflect perforating performance. To study porosity and permeability of damage zone in sandstone targets, the paper collected sandstone cores from the $3^{\text {rd }}$ section of the Zhuhai Formation to conduct a simulation experiment for HTHP perforation of large-size targets. After the simulation experiment, an automatic scanner was used to find the planar distribution of the porosity and permeability parameters of the $150^{\circ} \mathrm{C}$ perforation holes in the cores. The study led to two findings. First, the temperature has a minor effect on the hole depth and diameter in a specified scope. The hole depth decreases as the negative pressure increases and the depth decreases as the effective stress increases. Second, a UHP perforated sandstone target is remarkably zone-specific in planar distribution of the hole porosity and permeability. The damage zone can be divided into the fracture zone, the transition zone, the compaction zone and the undisturbed zone. Besides, the zone permeability damage was quantified. These findings can effectively support research on numerical value simulation for HTHP perforation holes. Besides, they can support HTHP well perforating design and improve near-wellbore permeability enhancement and plug removal.

Keywords: perforation hole, damage zone, sandstone target, porosity and permeability characteristic, UHT reservoir

\section{INTRODUCTION}

Over the years, quite a few perforated completion techniques have been developed for reservoir development (Zhu, et al., 2015) in China and beyond. These techniques include mainly deeppenetrating shaped charge perforating, underbalanced perforating, fracture perforating, ultrahigh pressure (UHP) perforating, sand jet perforating, oriented perforating, full-bore perforating and perforating processes, and auxiliary processes (Zhu, et al., 2013). The generalization of these applications is very effective in enhancing the efficiency of perforated completion and reservoir development (Zhu, et al., 2014). Using the concrete target to check the perforating and safety performance of the perforator is the most common practice under surface condition in China and beyond. Cement/sand performance, maintenance process and time length have a major effect on the 
concrete leading to poor internal homogeneity. In other words, different and individual test targets tend to have very heterogeneous internal structures. Judging from the current studies, concrete strength is an important factor affecting perforating performance. For example, every 6.9 MPa increase in compressive strength causes a 5-7\% decrease in the average hole depth. This suggests that characteristics of different concrete targets have a major effect on the test results. What make the steel target a better solution than the concrete target are good homogeneity, preparation simplicity/speed, and low cost. However, the physical properties of the steel target are drastically different from those of real reservoirs, unable to reflect the actual perforating process.

Berea sandstone in North America is the most used nature rock target in perforating simulation. Besides, rock outcrops in the Sichuan Basin and the Erdos Basin are also used for various tests and studies.

As early as 1952, Henry, 1952 perforated tight dolomitic sandstone specimens measuring $33 / 4$ inches in diameter and 10-12 inches in length with the common bullet and the shaped charge bullet for a comparative analysis of performance differences. In 1978, Saucier and Lands, 1978 evaluated the effect of crustal stress on the perforating parameters and flow efficiency according to API RP-43 standards. Halleck et al. systematically summarized the effects of the effective stress based on the findings of around 300 perforating operations in 120 tests. When a 3,000 psi effective stress was applied to the test target, the penetration effect of the bullet on the rock (not including casing and cement) fell by $10-14 \%$. The flow efficiency of the rock specimens decreased as the effective stress rose. In 2003, Karacan and Halleck, 2003 perforated Berea sandstone specimens with saturated gas (nitrogen) and liquid (silicone oil) respectively to analyze the differences of the porosity and permeability of compaction zones. The saturated nitrogenperforated specimens had a hole diameter of $0.5-0.7 \mathrm{~cm}$ and a hole depth of around $14 \mathrm{~cm}$, while the silicone oil-perforated specimens had a diameter of $1.2-1.4 \mathrm{~cm}$ and a hole depth of $16 \mathrm{~cm}$. In the saturated nitrogen-perforated specimens, the compression band thickness was around $6 \mathrm{~mm}$ at the opening and decreased incrementally as the hole depth increased, Meantime, compression band porosity was $6-8 \%$ lower than those of original rock specimens. By contrast, compression bands were not found in saturated silicone oilperforated specimens. Besides, perforating caused diagenetic particles to fracture. In the saturated nitrogen-perforated specimens, these particles were more seriously fractured. In 2008, Snider et al., 2008 used three different types of bullets to perforate 30 coal specimens, finding the hole depth to be far smaller than the predicted value of the existing sand rock hole models. Moreover, the hole diameter (0.07-0.32 in) was significantly smaller than that of common sandstone. In 2011, Grove et al., 2011 first summarized the inadequacies of the existing test and analysis methods in regard of CFE (Core Flow Efficiency) computation, concluding that the original methods generated greater errors. Therefore, they developed more reliable test methods and data processing methods to compute the flow efficiency, the effective permeability and

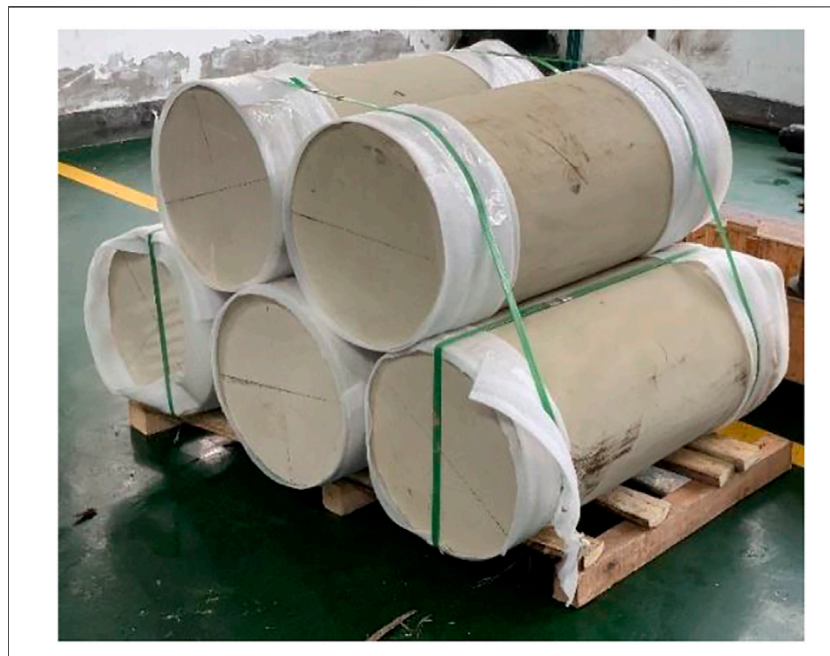

FIGURE 1 | Final experimental sandstone targets ( $\Phi 400 \mathrm{~mm})$.

thickness of the compression band. In 2012, Huang, 2012 worked with the Schlumberger Well Completion Center to conduct perforating test on Indiana limestone and analyzed the effect of rock strength on the penetration depth (or hole depth). They measured rock strength and hole depth under different confining pressures. By predicting the hole depth with the analytical method developed by Alekseevskii, they prepared graphs for the bullet speed and the penetration depth. In 2019, Brenden Grove et al., 2019 analyzed and evaluated the effect of the high-temperature, high-pressure (HTHP) reservoir condition of offshore oil fields on UHP pressure perforating.

Perforating simulation test is becoming incrementally complex. Homogeneous small-size steel targets and cement targets were used but were gradually replaced by large-size sandstone targets. Initially, single factors were the variables in perforating test and gradually multiple factors were used instead. Initially, perforating test was conducted under normal temperature and pressure (NTP) surface condition. Gradually more perforating tests were conducted under HTHP condition, a condition closer to oil and gas reservoir condition and it turned out that test results were more correct and reliable. Perforating simulation test has been broadly applied in perforating parameters acquisition, reservoir damage mechanism research, penetration depth-affecting factor evaluation, perforation hole geometry research, hole flow efficiency evaluation, bullet performance analysis, and evaluation of the effect of perforating on sand production.

At present, from the research on perforation by domestic and foreign scholars, it can be seen that the experimental research objects of perforation simulation are mainly concentrated on concrete, and the temperature is less considered. Therefore, the test results are difficult to reflect the real underground perforation situation. In view of the existing problems, the author uses the third-segment sandstone core of Zhuhai Formation to carry out physical simulation of large-size perforation under high temperature and high pressure, to study the characteristics of perforation 
TABLE 1 | Experimental plan investigating the effect of temperature on perforating.

\begin{tabular}{|c|c|c|c|c|c|c|}
\hline Experiment $\mathrm{S} / \mathrm{N}$ & Bullet type & $\begin{array}{c}\text { Target strength } \\
\text { (MPa) }\end{array}$ & Temperature $\left({ }^{\circ} \mathrm{C}\right)$ & $\begin{array}{l}\text { Confining pressure } \\
\text { (MPa) }\end{array}$ & $\begin{array}{l}\text { Negative pressure } \\
\text { (MPa) }\end{array}$ & Remarks \\
\hline 1 & $\mathrm{CN}-127-40 \mathrm{RT}-25-5\left(25^{\circ} \mathrm{C}\right)$ & 400 & 25 & 25 & 5 & Different temperatures \\
\hline 2 & $\mathrm{CN}-127-40 \mathrm{HT}-25-5\left(50^{\circ} \mathrm{C}\right)$ & & 50 & & & \\
\hline 3 & $\mathrm{CN}-127-40 \mathrm{HT}-25-5\left(100^{\circ} \mathrm{C}\right)$ & & 100 & & & \\
\hline 4 & $\mathrm{CN}-127-40 \mathrm{UHT}-25-5\left(150^{\circ} \mathrm{C}\right)$ & & 150 & & & \\
\hline
\end{tabular}

TABLE 2 | Experimental plan investigating the effect of negative pressure on perforating.

\begin{tabular}{|c|c|c|c|c|c|c|c|}
\hline $\begin{array}{l}\text { Experiment } \\
\mathrm{S} / \mathrm{N}\end{array}$ & Bullet type & $\begin{array}{c}\text { Target } \\
\text { strength (MPa) }\end{array}$ & $\begin{array}{l}\text { Temperature } \\
\text { ('C) }\end{array}$ & $\begin{array}{c}\text { Confining } \\
\text { pressure (MPa) }\end{array}$ & $\begin{array}{c}\text { Negative } \\
\text { pressure (MPa) }\end{array}$ & $\begin{array}{c}\text { Effective } \\
\text { stress (MPa) }\end{array}$ & Remarks \\
\hline 5 & $\begin{array}{l}\text { CN-127-40- } \\
\text { HT- } 25-5\end{array}$ & 40 & $\begin{array}{l}\text { Room } \\
\text { temperature }\end{array}$ & 25 & 5 & 20 & $\begin{array}{l}\text { Different negative pressures } \\
\text { under the same effective stress }\end{array}$ \\
\hline 6 & $\begin{array}{l}\text { CN-127-40- } \\
\text { HT-30-10 }\end{array}$ & & & 30 & 10 & & \\
\hline 7 & $\begin{array}{l}\text { CN-127-40- } \\
\text { HT-35-15 }\end{array}$ & & & 35 & 15 & & \\
\hline
\end{tabular}

TABLE 3 | Experimental plan investigating the effect of effective stress on perforating.

\begin{tabular}{|c|c|c|c|c|c|c|c|}
\hline $\begin{array}{l}\text { Experiment } \\
\text { S/N }\end{array}$ & Bullet type & $\begin{array}{c}\text { Target } \\
\text { strength (MPa) }\end{array}$ & $\begin{array}{l}\text { Temperature } \\
\text { ('C) }\end{array}$ & $\begin{array}{c}\text { Confining } \\
\text { pressure (MPa) }\end{array}$ & $\begin{array}{c}\text { Negative } \\
\text { pressure (MPa) }\end{array}$ & $\begin{array}{c}\text { Effective } \\
\text { stress (MPa) }\end{array}$ & Remarks \\
\hline 8 & $\begin{array}{l}\text { CN-127-40- } \\
\text { HT-20-10 }\end{array}$ & 40 & $\begin{array}{l}\text { Room } \\
\text { temperature }\end{array}$ & 20 & 10 & 10 & $\begin{array}{l}\text { Different effective stresses under } \\
\text { the same negative pressure }\end{array}$ \\
\hline 9 & $\begin{array}{l}\text { CN-127-40- } \\
\text { HT-25-10 }\end{array}$ & & & 25 & & 15 & \\
\hline 10 & $\begin{array}{l}\text { CN-127-40- } \\
\text { HT-30-10 }\end{array}$ & & & 30 & & 20 & \\
\hline 11 & $\begin{array}{l}\text { CN-127-40- } \\
\text { HT-35-10 }\end{array}$ & & & 35 & & 25 & \\
\hline
\end{tabular}

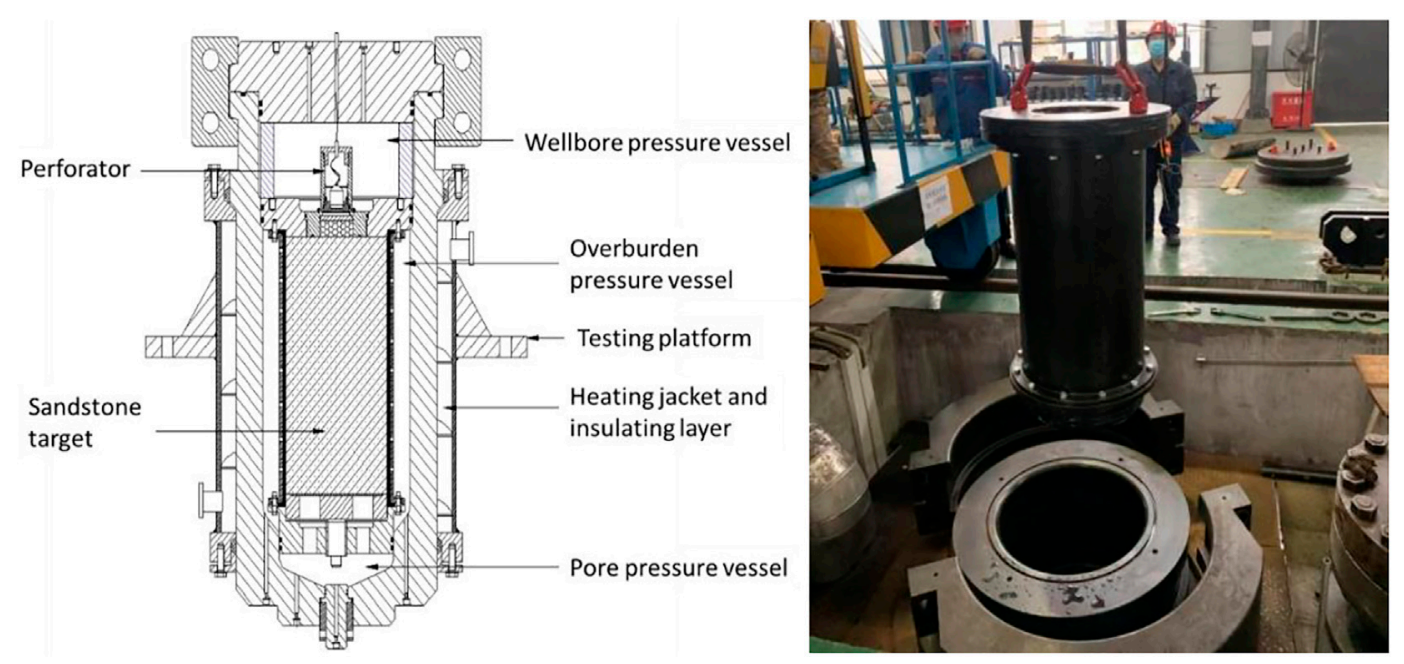

FIGURE 2 | Structural representation of the perforating performance experimental unit. 
A

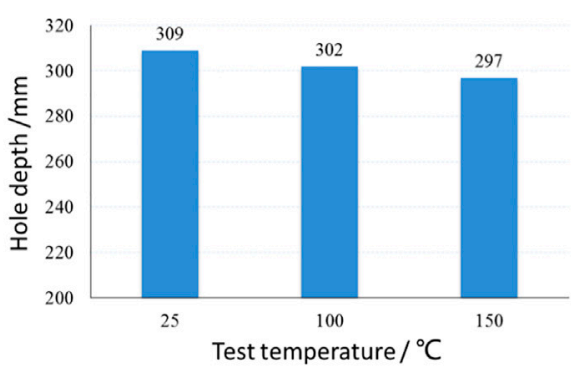

Effect of different temperatures on hole depth

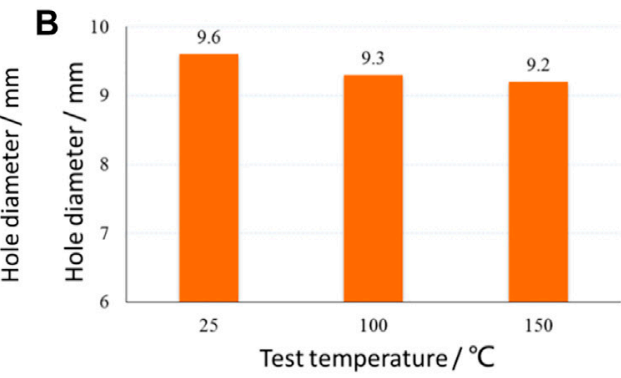

Effect of different temperatures on hole diameter

FIGURE 3 | Effect of different temperatures on hole size (depth and diameter). (A) Effect of different temperatures on hole depth (B) Effect of different temperatures on hole diameter.

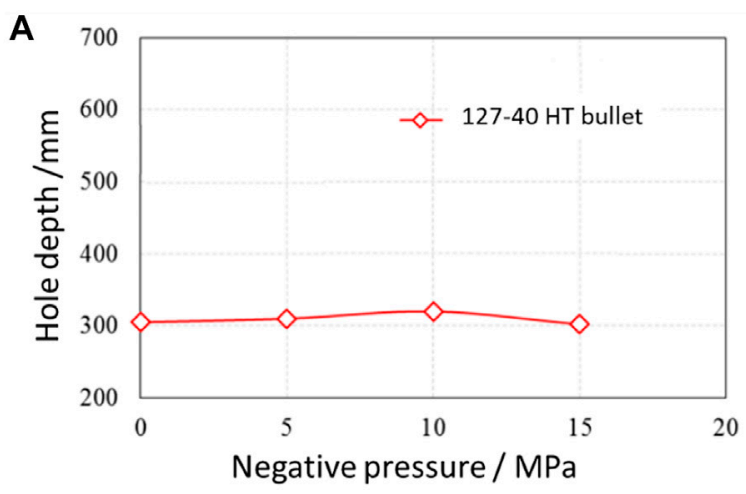

Effect of negative pressure on hole depth

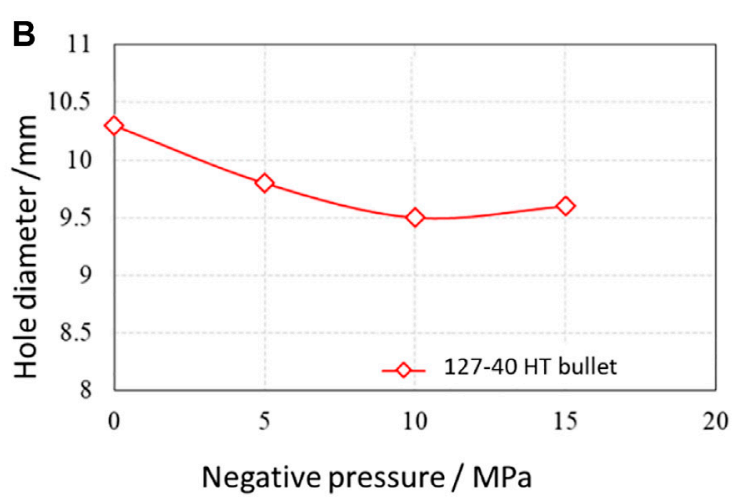

Effect of negative pressure on hole diameter

FIGURE 4 | Effect of negative pressure on hole size (depth and diameter) (Effective Stress: $20 \mathrm{MPa}$ ). (A) Effect of negative pressure on hole depth (B) Effect of negative pressure on hole diameter.

channel loss and permeability, and to provide a theoretical basis for on-site construction.

\section{EXPERIMENTAL SPECIMENS, MATERIALS, METHODS AND EQUIPMENT}

\subsection{Sandstone Target Characteristics}

For this paper, rock specimens extracted from the $2^{\text {nd }}$ section of the Zhuhai Formation were used for experimentation. According to $\log$ interpretation, the $2^{\text {nd }}$ section has a $8-11 \%$ rock porosity. The test has determined the permeability to be $2-5 \mathrm{mD}$ and the uni-axial compressive strength to be around $45 \mathrm{MPa}$. Figure 1 shows the final experimental sandstone specimens.

\subsection{Experimental Plan}

For this paper, sandstone cores were extracted from the $3^{\text {rd }}$ section of the Zhuhai Formation to physically simulate a large-size hole experiment which primarily studies the effect of three reservoir characteristics, such as temperature, negative pressure condition and effective formation stress, on the result of the perforating experiment.

\subsubsection{Effect of Different Temperatures}

$\mathrm{CN}-127$ bullets were used for sandstone cores with a $40 \mathrm{MPa}$ target strength. The hole density was $40 \mathrm{~m}$. Four temperature variables $\left(25^{\circ} \mathrm{C}, 50^{\circ} \mathrm{C}, 100^{\circ} \mathrm{C}\right.$ and $\left.150^{\circ} \mathrm{C}\right)$ were set under the same confining pressure of $25 \mathrm{MPa}$ and the same negative pressure of $5 \mathrm{MPa}$ Table 1.

\subsubsection{Effect of Negative Pressure}

$\mathrm{CN}-127$ bullets were used for sandstone cores with a $40 \mathrm{MPa}$ target strength. Three negative pressure variables $(5,10$ and $15 \mathrm{MPa})$ were set under the same effective stress of $20 \mathrm{MPa}$ Table 2.

\subsubsection{Effect of Negative Pressure}

CN-127 bullets were used for sandstone cores with a $40 \mathrm{MPa}$ target strength. Four negative pressure variables (10, 15, 20 and 


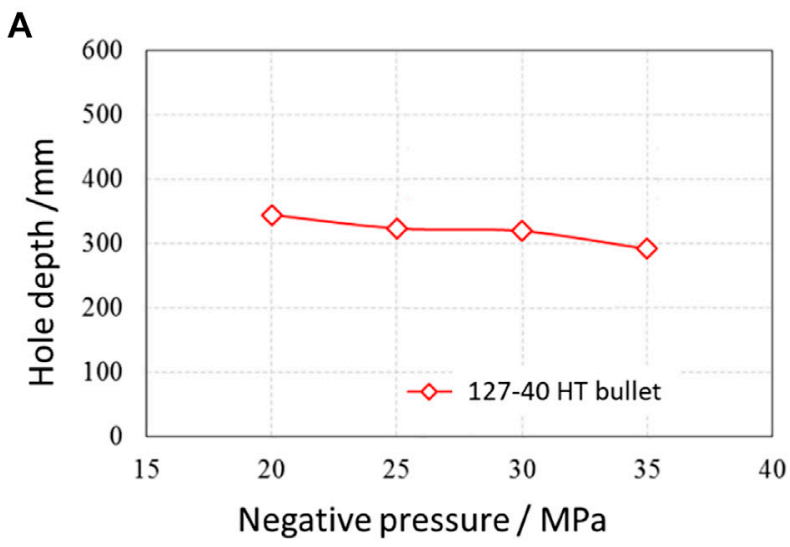

Effect of effective stress on hole depth

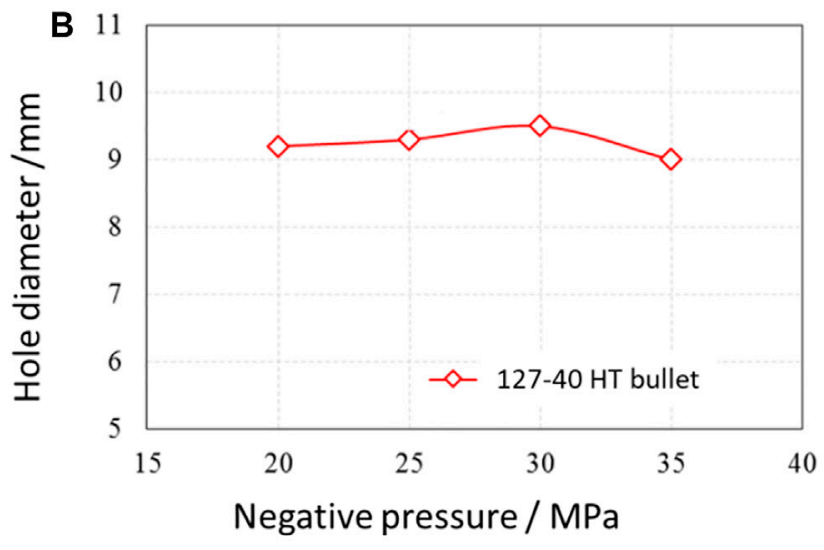

Effect of effective stress on hole depth

FIGURE 5|Effect of effective stress on hole size (Negative Pressure: $10 \mathrm{MPa}$ ). (A) Effect of effective stress on hole depth (B) Effect of effective stress on hole depth.

A

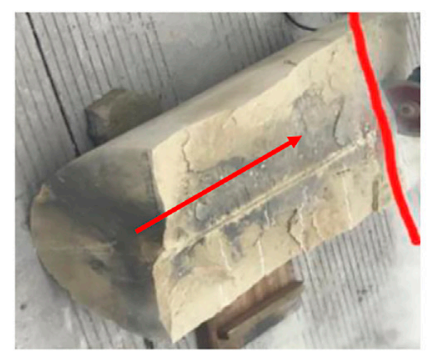

Original image of the hole in the target

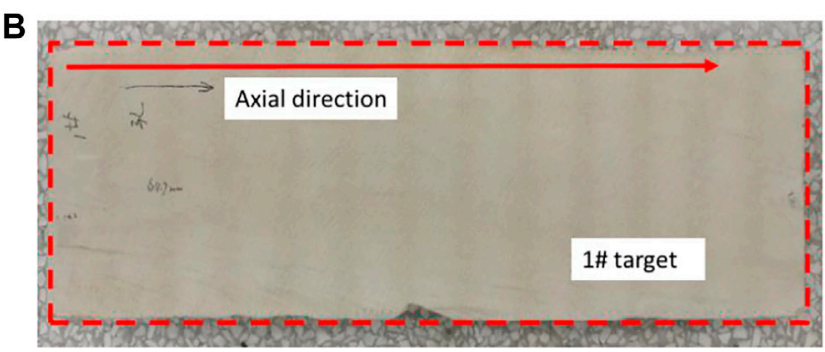

Axial planar sectional drawing

C
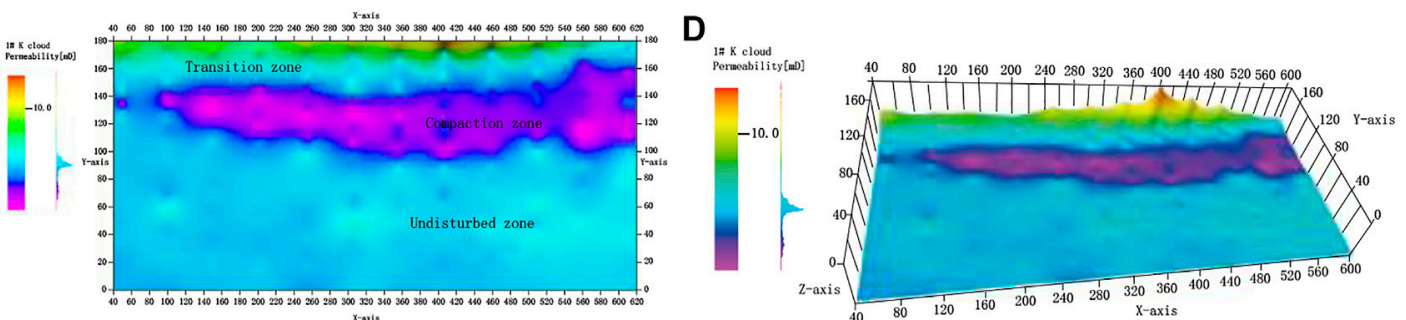

2D distribution characteristics of sandstone target permeability

3D distribution characteristics of sandstone target permeability

FIGURE 6 | Sandstone target specimens and respective permeability values [CN-127-40-HT-25-5 (100 $\mathrm{C})$ ]. (A) Original image of the hole in the target (B) Axial planar sectional drawing (C) 2D distribution characteristics of sandstone target permeability (D) $3 D$ distribution characteristics of sandstone target permeability.

$25 \mathrm{MPa}$ ) were set up under the same negative pressure of $10 \mathrm{MPa}$ Table 3.

\subsection{Perforating Simulation System for the Large-Size Hole}

The perforating simulation system, or perforating simulator, consists primarily of a perforating performance experimental unit, a nitrogen compressor system, a hydraulic pressure system, a heating and cooling system, and a central control and monitoring system. The perforating simulator can perform HT perforating test and pre-perforating and postperforating fluidity test for the sandstone target under threephase pressurization condition (wellbore pressure, overburden formation stress, and pore pressure). As indicated in Figure 2, the main features of the unit are a wellbore pressure vessel, a perforator, an overburden pressure vessel, a wellbore, and a pore pressure dampener. The unit can meet the requirements 

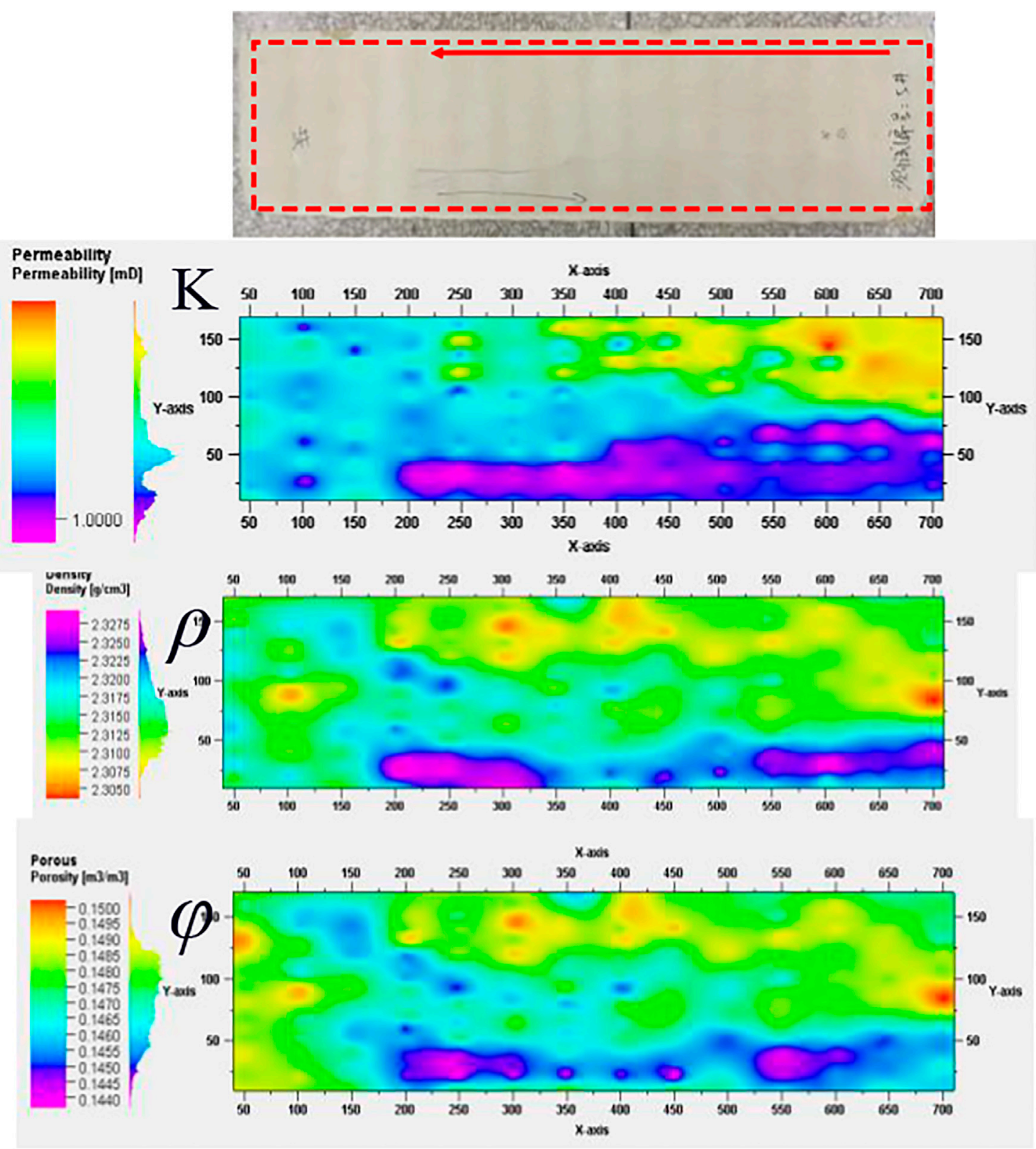

FIGURE 7 | Permeability-density-porosity axial planar distribution diagram [CN-127-40 HT-25-5 $\left.\left(100^{\circ} \mathrm{C}\right)\right]$.

for $\varphi 400 \mathrm{~mm} \times 800 \mathrm{~mm}$ sandstone targets at a maximum as well as an experimental pressure up to $100 \mathrm{MPa}$ and an experimental temperature up to $200^{\circ} \mathrm{C}$. The unit comprises primarily three main vessels (i.e., a wellbore pressure vessel, a confining pressure vessel and a pore pressure vessel), a perforator, a pressure separator, and a sandstone target.

The nitrogen compressor system consists of a set of highpressure nitrogen cylinders, a nitrogen compression and pressure experimental cabinet, and a high pressure valve. The rated pressure is $70 \mathrm{MPa}$. It works mainly to increase gas pressure inside the pore pressure vessel of the perforating performance experimental unit so as to simulate downhole reservoir pressure.
The hydraulic pressure system has a rated pressure of $100 \mathrm{MPa}$, consisting of a hydraulic pressure experimental cabinet, a high-pressure valve and others. The cabinet has three outlets, connected to the wellbore pressure vessel, the overburden pressure vessel and the pore pressure vessel, respectively. The pipe connected to the pore pressure vessel, arranged in parallel to the nitrogen compression pipe, can achieve gas/liquid conversion. The pressure pipes, all fitted with safety relief valves, has a $105 \mathrm{MPa}$ safety pressure setting. The booster pump system includes a highpressure pump and a LP pump. In low pressure (LP) condition (lower than $18 \mathrm{MPa}$ ), the heavy duty LP pump is used to boost pressure, while in high-pressure condition, light duty LP 


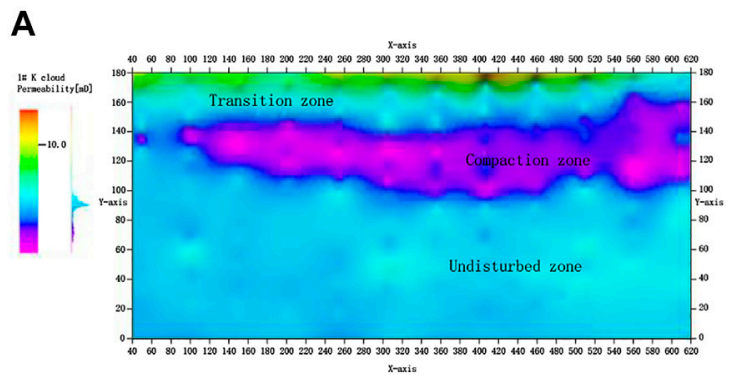

B Permeability distribution characteristics

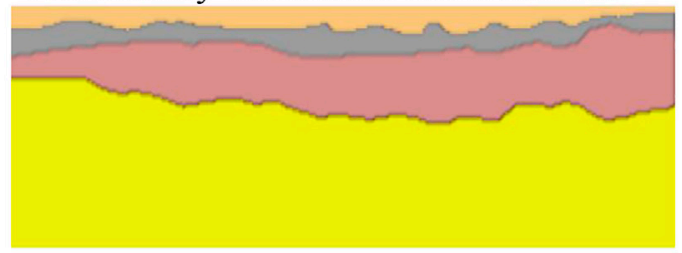

Zone-specific clustering analysis results

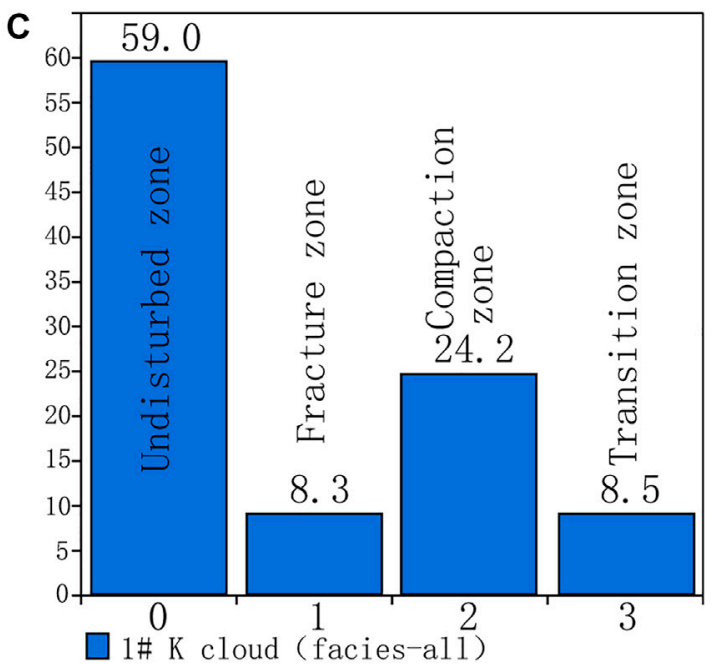

Percentage of the zones by area

FIGURE 8 | Hole damage area analysis [CN-127-40 HT-25-5 (150 $\mathrm{C})$ ]. (A) Permeability distribution characteristics (B) Zone-specific clustering analysis results (C) Percentage of the zones by area.

pump is used to boost pressure. This is intended to coordinate safety with time efficiency.

The heating and cooling system consists of a heater-cooler, HT steel pipes and accessories. The heater-cooler can heat the air and transfers it to the heating jacket to boost the temperature of the perforating performance experimental unit. At the same time, it transfers room-temperature air to the jacket for convective heat transfer and perforator cooling.

The central control and monitoring system consists of a microcomputer, a central control cubicle, a manual console, a PLC and electronic components, testing software, a temperature/pressure transducer and an electrical control cubicle. The microcomputer and the control cabinet are used mainly to supply or cut off electricity to the various electrical devices; gather, show and record the values of various parameters (e.g., temperature, pressure and flow); conduct temperature and pressure control for the major media inside the system; and set up safety voltage drop and alarm values.

\subsection{Automatic Core Porosity and Permeability Scanner}

Core porosity and permeability scanning is conducted following the perforating experiment. For different formations from which cores were extracted, porosity and permeability parameters were therefore obtained, to study characteristics of porosity and permeability of the damage zone.

A core porosity and permeability scanner includes a measuring probe which is pressed onto the surface of a specimen and injects compressed gas (normally nitrogen) through a hole. As the core is a homogeneous material, nitrogen will enter the limited specimen volume before being released hemispherically into the ambient air. The probe tip, made of soft silicone, can prevent nitrogen leaking from the specimen. The scanner injects steady-state nitrogen into the core specimen to find the permeability at any place. It can also find rock density and porosity by measuring $\mathrm{P}$-wave velocity $\left(\mathrm{V}_{\mathrm{p}}\right)$ and $\mathrm{S}$-wave velocity $\left(\mathrm{V}_{\mathrm{s}}\right)$. With steady-state air injection, the scanner can determine the permeability of any part of the specimen. It also allows for automatic continuous scanning of multiple parameters (e.g., permeability, resistivity, and wave velocity) of the core and slab. Besides, the scanner also realize convergence and analysis of multiparameter scanning data as well as logging curve correction.

The scanner is capable of permeability and P-wave and S-wave velocity scanning for the planar points, lines and planes of the sandstone target in an axial/radial direction. It can determine the target permeability, porosity, and rock density distribution changes of the target. Therefore, parameters of the perforating damage (e.g., shape, area and thickness) are determined macroscopically as a basis for subsequent CT/SEM scan of experimental specimens.

\section{LAW OF THE EFFECT OF DIFFERENT RESERVOIR CONDITIONS ON HOLE DIAMETER AND DEPTH}

\subsection{Effect of Temperature on Hole Diameter and Depth}

The CN_127-40 HT bullet perforating experiment was performed on sandstone targets with identical physical properties at different temperatures $\left(50,100\right.$ and $\left.150^{\circ} \mathrm{C}\right)$, under the confining pressure of $25 \mathrm{MPa}$ and the negative pressure of $5 \mathrm{MPa}$. In Figure 3, the bar charts of temperature, hole depth and dimensions of casing simulators (secondary target) were given according to the perforating experiment results. The bullet withstood a temperature of $160^{\circ} \mathrm{C} / 48 \mathrm{~h}$. When limited within the range of temperature tolerance, such 


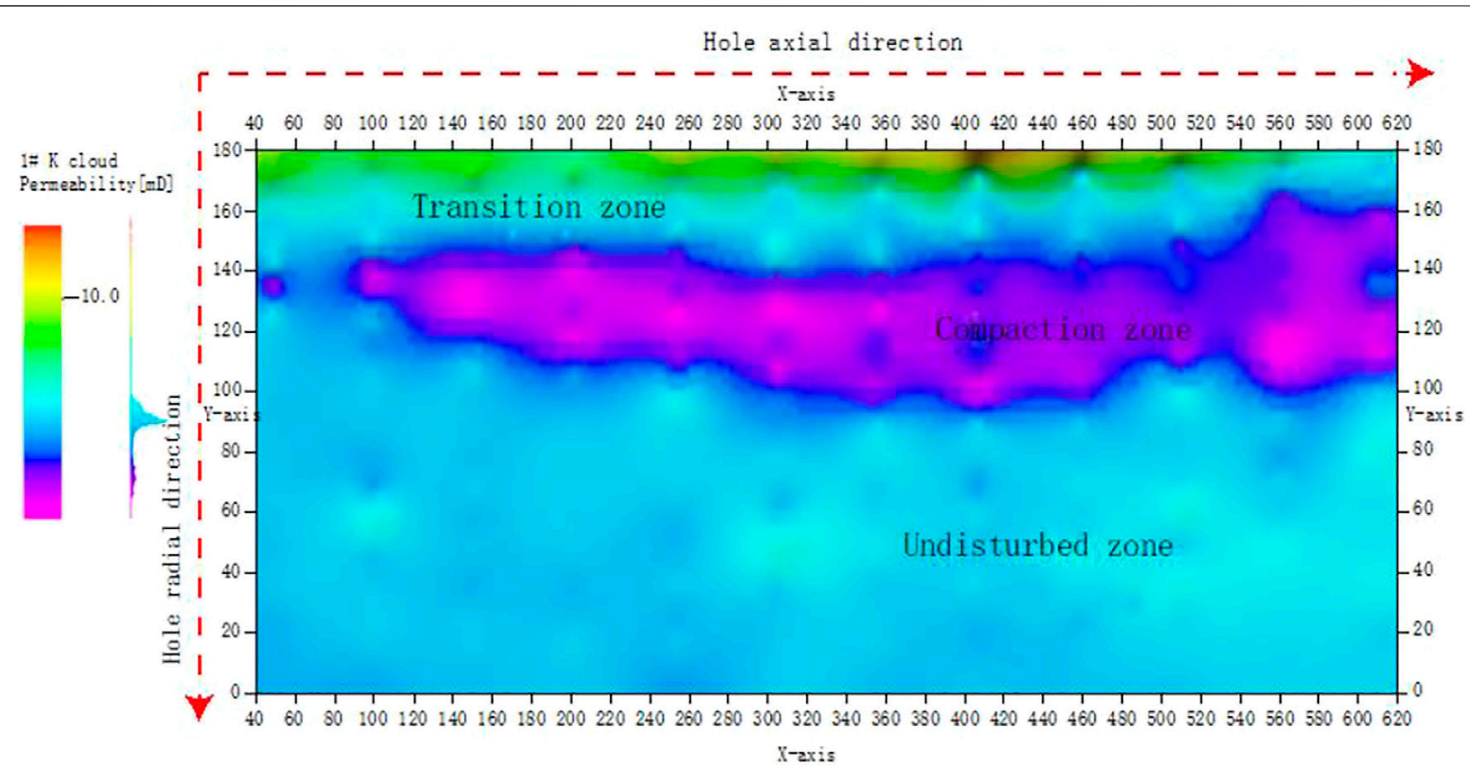

FIGURE 9 | Hole permeability distribution and radial direction analysis diagram [CN-127-40-UHT-25-5 $\left.\left(150^{\circ} \mathrm{C}\right)\right]$ (The black line represents the sampling position).

temperature had a small effect on both the depth and diameter of deep holes. When the temperature rose from 25 to $150^{\circ} \mathrm{C}$, the hole depth only decreased from 309 to $297 \mathrm{~mm}$ and the hole diameter only dropped by $0.4 \mathrm{~mm}$. This indicated a less-than-5\% change in hole depth and diameter.

\subsection{Effect of Decompression Condition on Hole Diameter and Depth}

The experiment gave the hole depth data at different negative pressures, finding that the negative pressure didn't have a significant effect on the depth of deep holes Figure 4A. Besides, Figure $4 \mathrm{~B}$ shows the effect of the negative pressure on the sandstone target on the hole diameter. Regardless of the rise in negative pressure, the hole diameter didn't change significantly.

\subsection{Effect of Effective Formation Stress on Hole Diameter and Depth}

As shown in Figure 5A, the hole depth decreased with the increase in the effective stress. With the effective stress on the sandstone target increasing from 20 to $35 \mathrm{MPa}$, the hole depth reduced by $53 \mathrm{~mm}$ (or $15.36 \%)$. However, seen from the effective stress-hole diameter correlation curve in Figure 5B, the effective stress had a minor effect on the overall hole diameter. An increase in the effective stress caused no significant changes to such diameter.

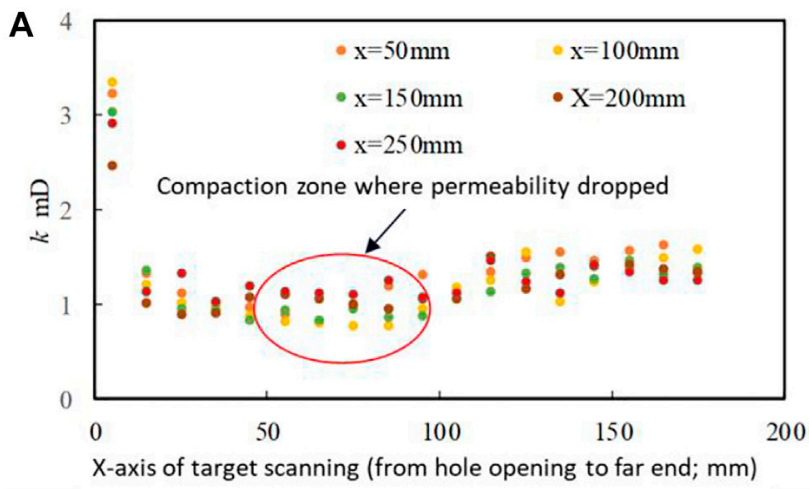

Absolute permeability changes

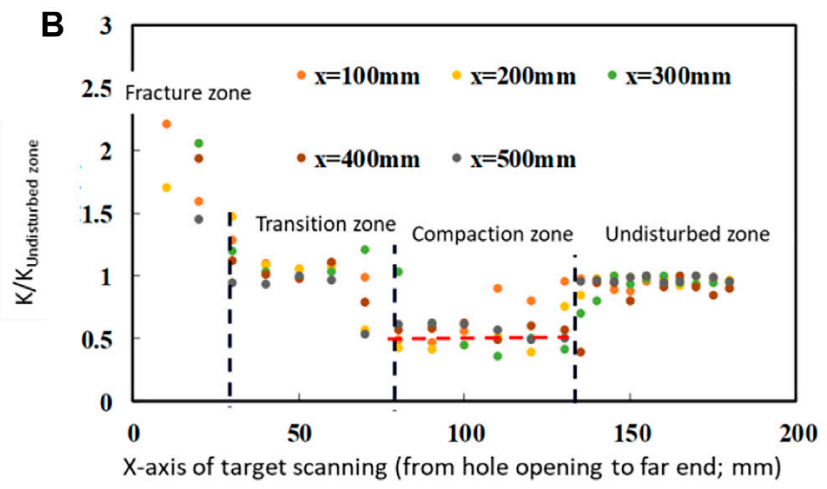

Relative permeability changes

FIGURE 10 | Curve of the directionless axial permeability changes in the radial direction [CN-127-40-UHT-25-5 (150 C)]. (A) Absolute permeability changes (B) Relative permeability changes 


\section{POROSITY AND PERMEABILITY DISTRIBUTION CHARACTERISTICS OF THE DAMAGE ZONE IN THE ULTRAHIGH PRESSURE TARGET PERFORATION HOLE}

\subsection{Acquisition of Rock Porosity and Permeability Planar Distribution Data in Different Parts of the Damage Zone}

A core scanner was used to obtain the characteristics of postperforating changes in target porosity, permeability, sound wave and density. The compaction zones were accurately classified and quantitatively evaluated. Since the different experimental groups have similar permeability distribution, the sandstone targets extracted using the $\mathrm{CN}-127-40 \mathrm{HT}$ bullet were the case under discussion.

Figure 6 shows the permeability of the sandstone specimen. For the purpose of scanning, a longitudinal section was cut off manually from the specimen. The permeability distribution was obviously zone-specific. To put it alternatively, there is an obvious high-permeability zone (fracture zone) and an obvious low-permeability zone (compaction zone) along the axis of the hole. By permeability distribution characteristics, the sandstone target was divided into the fracture zone, the transition zone, the compaction zone, and the undisturbed zone.

Core scanning returned the permeability values of the points, lines and planes as well as P-wave and S-wave velocity. Based on rock density and porosity, the P-wave and S-wave velocity measurements found the rock density and porosity typical of four bullet types. Then the density, porosity and permeability of the sandstone target were derived in the cloud diagram (Figure 7).

\subsection{Planar Distribution Characteristics of Rock Porosity and Permeability in the Damage Zone of the UHT Target Hole}

A cluster analysis of the planar distribution characteristics and sandstone target permeability test data found results of the target, perforating process and zone-specific cluster analysis. A column chart showing zone area percentages was also obtained.

\subsubsection{Planar Distribution Characteristics of UHT Target Porosity}

The cluster analysis was successfully made to automatically classify the target, perforated with the CN-127-40-HT-25-5 $\left(150^{\circ} \mathrm{C}\right)$ bullet, into zones based on permeability. Such parameters served to obtain the transverse wave and lengths of the zones, from which the thicknesses were obtained. The analytical findings show that the fracture zone accounts for $8.3 \%$ of the scanned area of the target, the transition zone accounts for $8.5 \%$ of the scanned area, and the compaction zone accounts for $24.2 \%$ of the scanned area. As shown in Figure 8, the average thickness of the fracture zone is $15.27 \mathrm{~mm}$ and the average thickness of the compaction zone is $44.53 \mathrm{~mm}$.

\subsubsection{Planar Permeability Distribution Characteristics of UHT and HT Targets}

Based on the studies of the target's planar characteristics, this paper further analyzed the target's changes in the radial/ dimensionless permeability along the hole at different positions (Figures 9, 10). According to the figures, the radial/ dimensionless permeability dropped from high (in the fracture zone) to low (in the compaction zone), and then rose to flat (in the undisturbed zone). Based on permeability change characteristics, the permeability values of different zones were determined. Then the average permeability was used to determine the permeability damage rate of the holes to be $44 \%$.

\section{CONCLUSION}

This paper involves sandstone cores extracted from the $3^{\text {rd }}$ section of the Zhuhai Formation to study the multidimensional porosity characteristics of the damage zone in sandstone target holes in different reservoir conditions. A physical simulation experiment with large-size perforation holes was conducted using various variables, such as temperature, negative pressure and effective formation stress. Then a core porosity and permeation analysis was conducted to find the planar distribution characteristics of porosity and permeation of the cores.

The study has led to the following conclusion.

Judging from the macroscopic parameters of the perforated sandstone targets, temperature has a minor effect on the hole depth and diameter, with only a change of. The negative pressure also has a small effect on the hole depth and diameter. As the effective stress increases, the depth of the hole made by CN_12740 - HT bullet reduced by $15.36 \%$ (equal to $53 \mathrm{~mm}$ ). Overall, the effective formation stress has a small effect on hole diameter.

Microscopically, the planar distribution of the hole porosity and permeation demonstrates is obviously zone-specific. There are four zones: the fracture zone, the transition zone, the compaction zone and the undisturbed zone.

Along the radial direction of the holes, the radial/ dimensionless permeability drops from high (in the fracture zone) to low (in the compaction zone), and then rose to even (in the undisturbed zone). Calculations find that permeability damage rate of the holes is $44 \%$.

\section{DATA AVAILABILITY STATEMENT}

The original contributions presented in the study are included in the article/Supplementary Material, further inquiries can be directed to the corresponding author.

\section{AUTHOR CONTRIBUTIONS}

HL has completed the ideas and research goals and aims, as well as conduct the data curation and the original Draft. CX has done the validation of experiments and the review and editing or the draft. SG has done the formal analysis and the supervision of experiments. 


\section{REFERENCES}

Grove, B., DeHart, R., McGregor, J., Dennis, H., and Christopher, C. (2019). "Operators Optimize High-Pressure/High-Temperature and UltrahighPressure Perforation Strategies Using Laboratory Testing," in Offshore Technology Conference, Houston, Texas, May 2019.

Grove, B., Harvey, J., Zhan, L., and Atwood, D. (2011). "Translating Perforating Laboratory Results to the Downhole Environment," in SPE European Formation Damage Conference, Noordwijk, The Netherlands, June 2011.

Henry, L. (1952). Experimental Evaluation of Well Perforation Methods as Applied to Hard limestone. Pet. Trans. 4, 163-168.

Huang, H. (2012). Effects of High Pressure Strength of Rock Material on Penetration by Shaped Charge Jet. AIP Conf. Proc. 1426, 1153. doi:10.1063/ 1.3686484

Karacan, C. Ö., and Halleck, P. M. (2003). Comparison of Shaped-Charge Perforating Induced Formation Damage to Gas- and Liquid-Saturated sandstone Samples. J. Pet. Sci. Eng. 40, 61-75. doi:10.1016/s0920-4105(03)00084-6

Saucier, R. J., and Lands, J. F. (1978). A Laboratory Study of Perforations in Stressed Formation Rocks. J. Pet. Technol. 30, 1347-1353.

Snider, P. M., Walton, I. C., Skinner, T. K., and Atwood, D. C. (2008). First Laboratory Perforating Tests in Coal Show lower-Than-expected Penetration. SPE Drilling \& Completion 23, 93-99. doi:10.2118/102309-MS

Zhu, H. Y., Deng, J., Jin, X., Hu, L., and Luo, B. (2015). Hydraulic Fracture Initiation and Propagation from Wellbore with Oriented Perforation. Rock Mech. Rock Eng. 48 (2), 585-601. doi:10.1007/s00603-014-0608-7
Zhu, H. Y., Deng, J. G., Chen, Z. J., An, F. C., Liu, S. J., Peng, C. Y., et al. (2013) Perforation Optimization of Hydraulic Fracturing of Oil and Gas Well. Geomech. Eng. 5 (5), 463-483. doi:10.12989/gae.2013.5.5.463

Zhu, H. Y., Deng, J. G., Liu, S. J., Wen, M., Peng, C. Y., Li, J. R., et al. (2014). Hydraulic Fracturing Experiments of Highly Deviated Well with Oriented Perforation Technique. Geomech. Eng. 6 (2), 153-172. doi:10.12989/gae.2014.6.2.153

Conflict of Interest: Author HL and SG are employed by CNOOC (China) Co. Ltd.

The remaining authors declare that the research was conducted in the absence of any commercial or financial relationships that could be construed as a potential conflict of interest.

Publisher's Note: All claims expressed in this article are solely those of the authors and do not necessarily represent those of their affiliated organizations, or those of the publisher, the editors and the reviewers. Any product that may be evaluated in this article, or claim that may be made by its manufacturer, is not guaranteed or endorsed by the publisher.

Copyright (C) $2022 \mathrm{Xu}$, Liang and Guo. This is an open-access article distributed under the terms of the Creative Commons Attribution License (CC BY). The use, distribution or reproduction in other forums is permitted, provided the original author(s) and the copyright owner(s) are credited and that the original publication in this journal is cited, in accordance with accepted academic practice. No use, distribution or reproduction is permitted which does not comply with these terms. 